\title{
Glycothermally Synthesized Self-aggregated ZnS Spherical Particles for Methyl Orange Photodecomposition
}

\author{
Sang-Jun Park ${ }^{1}$ and Jeong-Hwan Song, ${ }^{2, *}$ \\ ${ }^{1}$ Department of Materials Engineering, Graduate School of PaiChai University, Daejeon 35345, Republic of Korea \\ ${ }^{2}$ Department of Materials Science \& Engineering, PaiChai University, Daejeon 35345, Republic of Korea
}

\begin{abstract}
Using ethylene glycol $\left(\mathrm{C}_{2} \mathrm{H}_{6} \mathrm{O}_{2}\right)$ as the solvent, $\mathrm{ZnS}$ particles were synthesized in high yield at a relatively low temperature of $125^{\circ} \mathrm{C}$ via the glycothermal method. We report a facile method for preparing spherical self-aggregated $\mathrm{ZnS}$ particles from $\mathrm{ZnS}$ nanocrystals, using zinc acetate as the $\mathrm{Zn}^{2+}$ source and thiourea as a sulfur source, without mineralization or other agents. The crystal phase structure, morphology, size, surface chemical composition, and optical properties of the self-aggregated $\mathrm{ZnS}$ particles were characterized using XRD, FE-SEM, TEM, XPS, BET, and UV-Vis absorption. The ZnS particles had a cubic phase zinc blende structure without any other impurities. The average crystallite size of the synthesized primary nanocrystal, estimated from XRD peak width and TEM images, was nearly $4 \mathrm{~nm}$. FE-SEM images showed that all of the $\mathrm{ZnS}$ consisted of self-aggregated particles with a spherical morphology and a size of approximately $0.2 \mu \mathrm{m} \sim 0.5 \mu \mathrm{m}$, and contained many tiny primary nanocrystals. The prepared $\mathrm{ZnS}$ exhibited strong photoabsorption in the UV region. The optical band gap decreased from $3.85 \mathrm{eV}$ to $3.62 \mathrm{eV}$ as the glycothermal reaction temperature was increased, due to improvement in particle size and crystallization. The effects of the glycothermal reaction temperature on the photocatalytic activity of the synthesized selfaggregated $\mathrm{ZnS}$ particles were investigated by the photodecomposition of methyl orange (MO) dye under UV illumination $(\lambda=365 \mathrm{~nm})$. The prepared $\mathrm{ZnS}$ exhibited excellent photocatalytic degradation with increasing reaction temperature, of $125^{\circ} \mathrm{C}(5 \%), 150{ }^{\circ} \mathrm{C}(10 \%), 175^{\circ} \mathrm{C}(60 \%)$, and $200{ }^{\circ} \mathrm{C}(90 \%)$ after irradiation for 60 min. It was found that the $\mathrm{ZnS}$ particle prepared at $200^{\circ} \mathrm{C}$ achieved the highest photocatalytic degradation, with nearly $100 \%$ MO decomposition after $90 \mathrm{~min}$, by various photogenerated radical scavengers.
\end{abstract}

(Received June 9 2021; Accepted July 6, 2021)

Keywords: Self-aggregated ZnS, glycothermal, ethylene glycol, methyl orange, photodecomposition

\section{Introduction}

$\mathrm{ZnS}$, one of the II-VI semiconductor compounds with a polymorph crystal structure, is a material with a wide bandgap energy $(3.5 \mathrm{eV} \sim 3.7 \mathrm{eV}$ for the zinc-blende structure and $3.7 \mathrm{eV} 3.9 \mathrm{eV}$ for the wurtzite structure) and a large exciton binding energy of $40 \mathrm{meV}$. Because it has excellent optical and semiconductor properties, it can be used in a range of fields, for electroluminescence, light-emitting diodes, gas sensors, solar cells, bio devices, and ultraviolet light-based photosensors and photodetectors [1-9]. In addition, the

- 송정환: 교수, 박상준: 석사

*Corresponding Author: Jeong-Hwan Song

[Tel: +82-42-520-5916, E-mail: song_jeonghwan@pcu.ac.kr]

Copyright (c) The Korean Institute of Metals and Materials photocatalytic properties of $\mathrm{ZnS}$ have attracted particular attention, given its high efficiency and chemical stability, properties which make it suitable for treating non-degradable and toxic pollutants present in wastewater [10-12].

Recently, various approaches to synthesize $\mathrm{ZnS}$ have been attempted, including solid-state reaction [13], the precipitation method [14], the sol-gel method [6], chemical bath deposition [10], the microwave method [15], the vaporliquid-solid (VLS) synthesis method [16], and the hydrothermal method $[17,18]$. The above methods require complex equipment and processes to manufacture the powder; in addition, a significant amount of energy is required to obtain crystalline powder.

As an alternative, a method similar to the hydrothermal method, the glycothermal method, can be used for 
synthesizing anhydrous crystalline materials in a nonaqueous solvent, using various glycols (1,4-butanediol, diethylene glycol, ethylene glycol, etc.), and dihydric alcohol, rather than water. The method has been employed in attempts to produce various powders $[19,20]$. Compared to the hydrothermal method, the glycothermal reaction can be performed at both lower temperature and pressure. The shape and size of the powder can be easily controlled without growth directing agents in a short reaction time. Inorganic mineralizers $(\mathrm{KOH}, \mathrm{NaOH}$, etc.), which can cause contamination, are not required. The glycothermal method does directly cause the formation of anhydrous crystalline materials in some cases, because glycols as a solvent can complex ions to promote solubility. Therefore, the role in terms of the properties of various glycols as a solvent is very important. However, the reaction mechanisms in nonaqueous solution are complex, and currently there is very limited information regarding the reaction thermodynamics, kinetics, and underlying crystallization mechanisms.

In this study, $\mathrm{ZnS}$ crystalline particle was produced using the glycothermal method with ethylene glycol as a reaction solvent. A simple process of direct glycothermal treatment in a solution in which a starting material was dissolved was used for synthesis at each reaction temperature. The properties of the synthesized particle were evaluated. $\mathrm{ZnS}$ has excellent optical properties due to the rapid generation of electron-hole pairs by photo-excitation and the high negative reduction potential of the excitation electrons, so it can be used as a photocatalytic material. To confirm the photodecomposition effect of organic pollutants, its photocatalytic properties were evaluated using an ultraviolet light source.

\section{Experimental Procedure}

In this study, zinc acetate dihydrate (Junsei, 99\%) and thiourea $\left(\mathrm{NH}_{2} \mathrm{CSNH}_{2}\right.$, DC Chemical, $\left.98 \%\right)$ were used as the starting materials with $\mathrm{Zn}$ and $\mathrm{S}$ to synthesize $\mathrm{ZnS}$ particles using the glycothermal method. The reaction solvent was ethylene glycol (Duksan, 99\%). After sufficiently dissolving the zinc acetate dihydrate and thiourea in $70 \mathrm{ml}$ of ethylene glycol at $0.02 \mathrm{~mol}$ each, the dissolved solution was put into an autoclave apparatus with a $100 \mathrm{ml}$ Teflon container and subjected to the glycothermal treatment. Particles were synthesized at each reaction temperature, with a heating jacket used for the glycothermal reaction. The synthesized precipitates were centrifuged three times for 15 minutes at $8000 \mathrm{rpm}$ using ethanol to separate and wash the reaction solvent. After drying for 12 hours in a dryer at $100{ }^{\circ} \mathrm{C}$, the final $\mathrm{ZnS}$ particle was obtained.

The crystal structure of the prepared $\mathrm{ZnS}$ particles were checked using an X-ray diffractometer (XRD, SmartLab, Rigaku, Japan) $\left(\mathrm{CuK} \alpha_{1}, 45 \mathrm{kV} / 200 \mathrm{~mA}, 4 \% \mathrm{~min}, 2 \theta=10\right.$ $80^{\circ}$ ). The particle shape and its components were observed with a field emission scanning electron microscope (FESEM, S-4800, Hitachi, Japan) using energy dispersive spectroscopy (EDS), and a transmission electron microscope (TEM, JEM-2100F, Jeol, Japan) was used to observe the dispersibility and crystal phase of the synthesized particle. To check the composition and chemical bonding state on the particle's surface, an X-ray photoelectron spectroscope (XPS, MultiLab, ESCA 2000) with an Al-K $\alpha$ monochromator as an $\mathrm{X}$-ray source and a concentric hemispherical analyzer was used. To measure the specific surface area of the particle, it was analyzed in a nitrogen atmosphere using BET (ASAP 2020, Micromeritics, USA). In addition, the optical properties of the $\mathrm{ZnS}$ particle obtained at each reaction temperature were analyzed and evaluated at room temperature using an ultraviolet-visible spectrophotometer (V-550, JASCO, Japan).

To investigate the photocatalytic properties of the $\mathrm{ZnS}$ particles obtained at each reaction temperature, a photodecomposition experiment was performed on an organic dye in a $10 \mathrm{ppm}$ methyl orange (MO) aqueous solution. $100 \mathrm{ml}$ of MO aqueous solution with $0.5 \mathrm{~g}$ of $\mathrm{ZnS}$ particle was irradiated while stirring in a dark room using a $30 \mathrm{~W}$ ultraviolet BLB lamp with a wavelength of $365 \mathrm{~nm}$ as an excitation source. In addition, to prevent the MO aqueous solution being evaporated by the heat generated from the UV lamp, it was kept at room temperature using a cooling reactor. The photodecomposition reaction of the MO organic dye was carried out for 30,60, 90, 120, 150 minutes, 3 hours, and 4 hours. After separating the $\mathrm{ZnS}$ particles using a centrifuge to ensure they were not mixed, the aqueous solution was collected and put into a quartz cell following the photodecomposition reaction for each duration. Then, UV spectroscopy $(300 \mathrm{~nm} \sim 650 \mathrm{~nm})$ was performed to evaluate the photodecomposition characteristics of the MO organic dyes. 


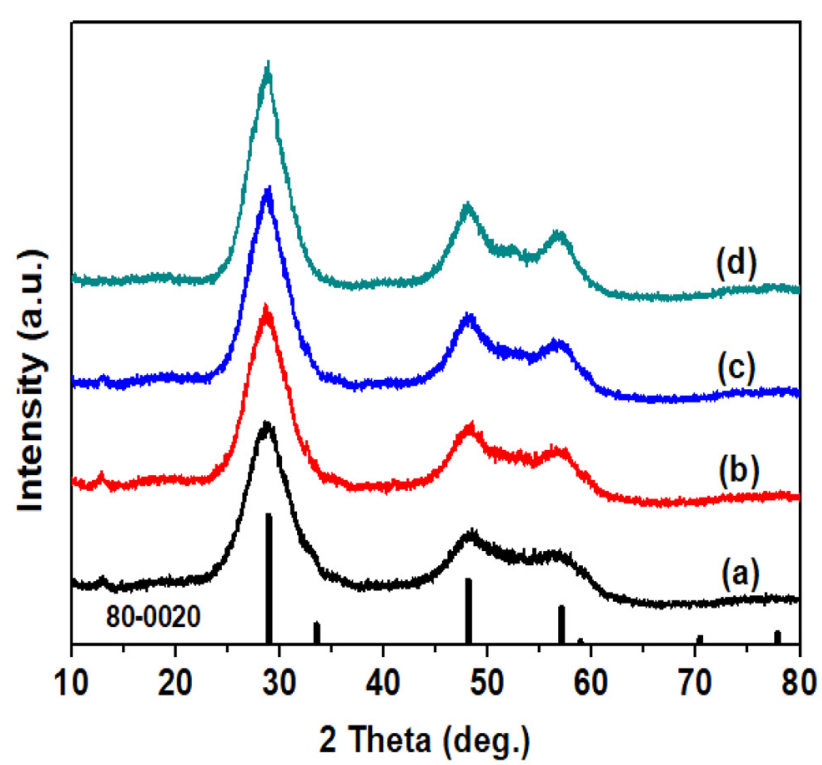

Fig. 1. XRD patterns of the self-aggregated $\mathrm{ZnS}$ particles obtained by the glycothermal method at (a) $125^{\circ} \mathrm{C}$, (b) $150^{\circ} \mathrm{C}$, (c) $175^{\circ} \mathrm{C}$, and (d) $200^{\circ} \mathrm{C}$ for $1 \mathrm{~h}$.

\section{Results and Discussion}

The $\mathrm{ZnS}$ particles obtained at reaction temperatures between $125^{\circ} \mathrm{C}$ and $200{ }^{\circ} \mathrm{C}$ were subjected to an XRD analyses of their crystal structure, and the results are shown in Fig. 1. $\mathrm{ZnS}$ was not synthesized at a reaction temperature of $100^{\circ} \mathrm{C}$ or less, and crystalline pure $\mathrm{ZnS}$ was synthesized at a reaction temperature of $125^{\circ} \mathrm{C}$ or higher, a relatively low temperature. The main peaks of the synthesized $\mathrm{ZnS}$ XRD pattern were (111), (220), and (311), which correspond to $28.7^{\circ}, 48.1^{\circ}$, and $57.0^{\circ}$, and the lattice constant of $\mathrm{ZnS}$ calculated from the (111) diffraction peak showed that $\mathrm{ZnS}$ particles with a zinc-blende crystal structure of $5.38 \AA$ was synthesized (JCPDS No. 80-0020). As the reaction temperature increased, the intensity of the XRD peak of the $\mathrm{ZnS}$ particles rose slightly, indicating that they had excellent crystallization. In addition, the produced $\mathrm{ZnS}$ particles had a wide full width at half maximum (FWHM) of the XRD peak regardless of the reaction temperature, and the average particle size calculated using Scherrer's equation was approximately $4 \mathrm{~nm}$ [21].

Fig. 2 shows an FE-SEM image of the $\mathrm{ZnS}$ particles produced by glycothermal treatment for 1 hour at each reaction temperature. In general, the reaction temperature
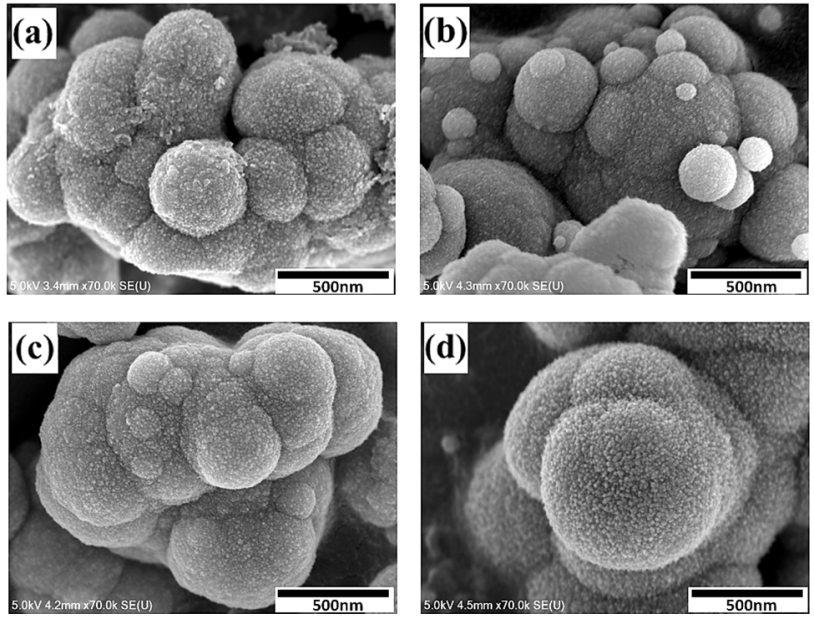

Fig. 2. FE-SEM images of the self-aggregated $\mathrm{ZnS}$ particles obtained by the glycothermal method at (a) $125^{\circ} \mathrm{C}$, (b) $150^{\circ} \mathrm{C}$, (c) $175^{\circ} \mathrm{C}$, and (d) $200{ }^{\circ} \mathrm{C}$ for $1 \mathrm{~h}$.

affects the growth and movement speed of the initial $\mathrm{ZnS}$ particles, and the particle diameter distribution [22]. When the reaction temperature of the precursor solution increases, thiourea is decomposed and it slowly and uniformly generates $\mathrm{S}^{2-}$ ions, after which $\mathrm{Zn}^{2+}$ ions react with $\mathrm{S}^{2-}$ ions to form $\mathrm{ZnS}$ nanocrystals. The $\mathrm{ZnS}$ particles produced at all reaction temperatures are formed by a continuous supply of uniform $\mathrm{ZnS}$ nanocrystals of primary particles, due to glycothermal reaction. These nanocrystals move to selfaggregate with each other and then form regular spherical secondary particles of sub-micron size. At a relatively low reaction temperature, spherical secondary particles with nonuniform sizes from $0.1 \mu \mathrm{m}$ to $0.5 \mu \mathrm{m}$ reacted with each other to form agglomerated $\mathrm{ZnS}$ particles. The formation and movement speed of the primary nanocrystals increased as the reaction temperature increased to $200{ }^{\circ} \mathrm{C}$, and it was found that the size of the spherical secondary particles gradually grew to about $0.7 \mu \mathrm{m}$ without changing shape, due to their self-aggregation with each other. In addition, it was found that the size of the initial $\mathrm{ZnS}$ nanocrystals on the surface of the spherical self-aggregated $\mathrm{ZnS}$ particles did not change, even when the reaction temperature was increased. It was further found that the porosity of the $\mathrm{ZnS}$ particles increased slightly. It is thought that the spherical self-aggregated $\mathrm{ZnS}$ particles formed through the self-aggregation process, followed by the Oswald aging process, because no additives such as surfactants or capping agents were used in this study [23]. 

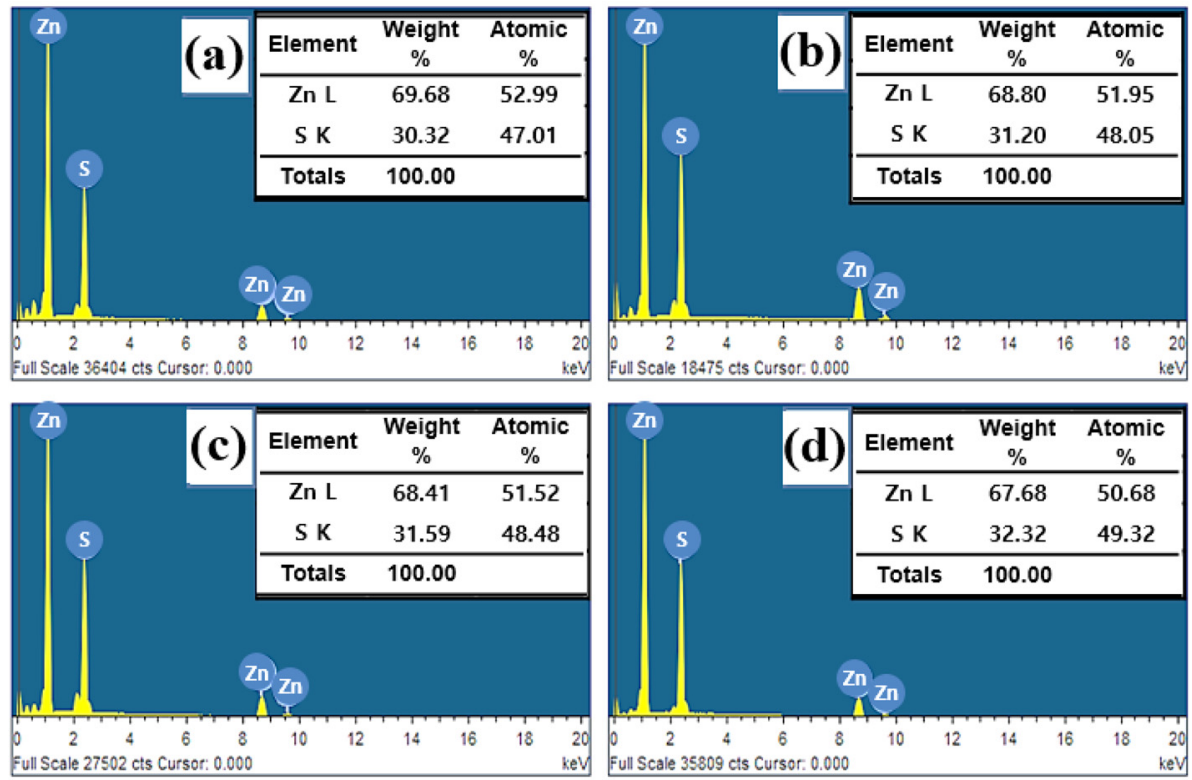

Fig. 3. EDS analysis of the self-aggregated $\mathrm{ZnS}$ particles prepared by the glycothermal method at (a) $125^{\circ} \mathrm{C}$, (b) $150{ }^{\circ} \mathrm{C}$, (c) $175{ }^{\circ} \mathrm{C}$, and (d) $200{ }^{\circ} \mathrm{C}$ for $1 \mathrm{~h}$.

Fig. 3 shows the EDS analysis results for the ZnS particles produced at each glycothermal reaction temperature. The EDS spectra of all the particles consisted of only $\mathrm{Zn}$ and $\mathrm{S}$ elements. At $125^{\circ} \mathrm{C}$, where the reaction temperature was relatively low, a $\mathrm{ZnS}$ particle lacking $\mathrm{S}$ was produced, as the atomic ratio of $\mathrm{Zn}$ to $\mathrm{S}$ was approximately 1:0.89. As the reaction temperature increased, the content of $\mathrm{S}$ increased, and a compound was found where the atomic ratio of $\mathrm{Zn}$ to $\mathrm{S}$ was close to a stoichiometric ratio of approximately 1:1.
Fig. 4 shows typical XPS results, analyzing the chemical bonding state of the constituent elements of self-aggregated $\mathrm{ZnS}$ particles produced through the glycothermal method at $200{ }^{\circ} \mathrm{C}$ for 1 hour. The spectra of $\mathrm{Zn}$ and $\mathrm{S}$ were observed. Internally, the spectral position of binding energy was used as a reference for calibration, based on the $\mathrm{C} 1 \mathrm{~s}$ of $284.5 \mathrm{eV}$ of the surface adventitious carbon. The weak spectra of $\mathrm{C}$ and $\mathrm{O}$ are considered to be from contamination when the particle surface was exposed to air. The peak of $\mathrm{O} 1 \mathrm{~s}$ at $531.5 \mathrm{eV}$
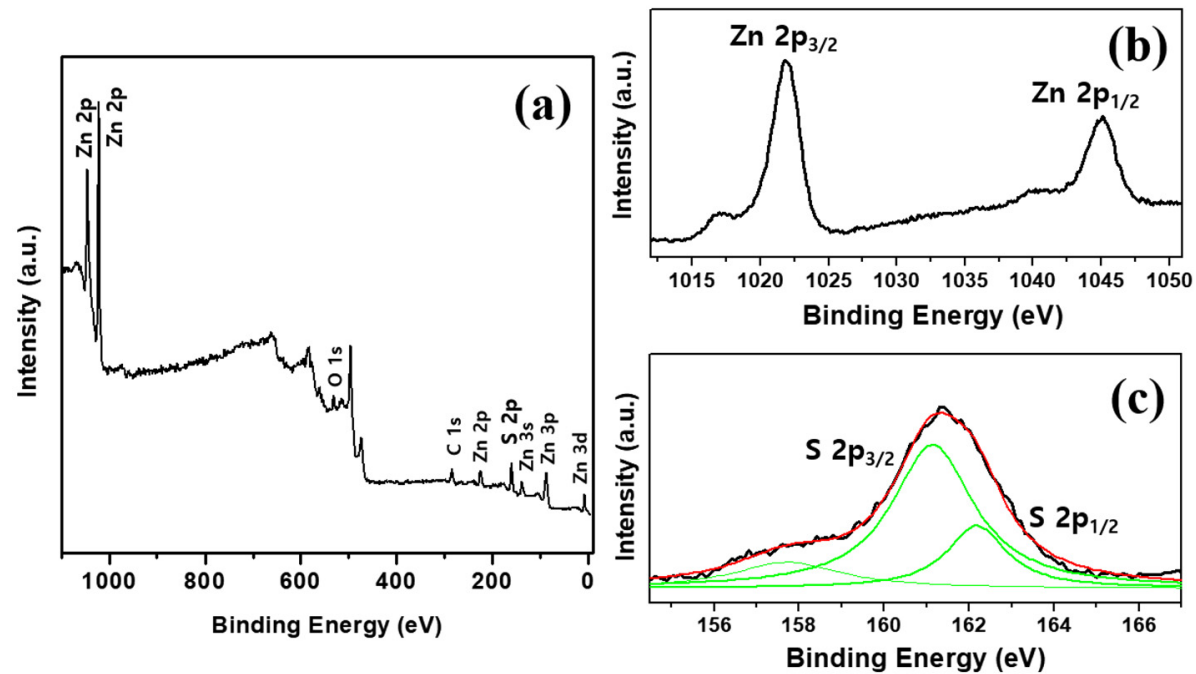

Fig. 4. XPS spectra of the $\mathrm{ZnS}$ particle synthesized by the glycothermal method at $200{ }^{\circ} \mathrm{C}$ for $1 \mathrm{~h}$ : (a) survey spectrum, (b) $\mathrm{Zn} 2 \mathrm{p}$ region spectrum, and (c) $S$ 2p region spectrum. 


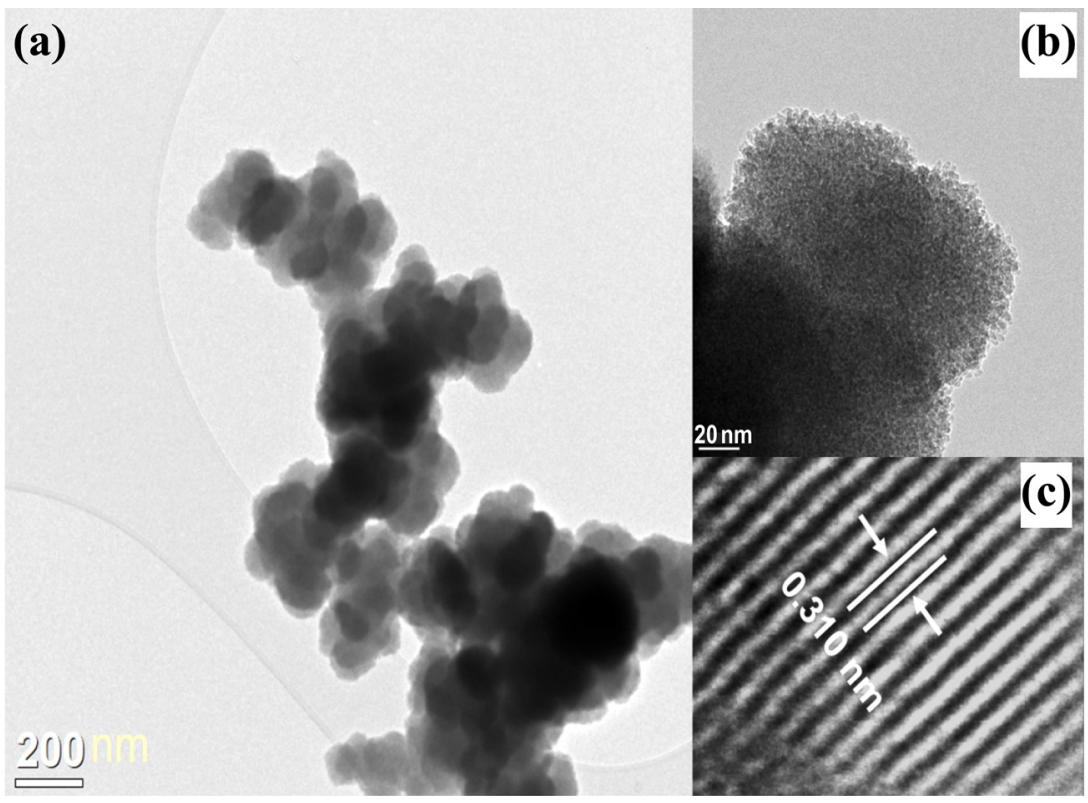

Fig. 5. (a) TEM, (b) HRTEM image, and (c) lattice fringe of the self-aggregated ZnS particle synthesized by the glycothermal method at $200{ }^{\circ} \mathrm{C}$ for $1 \mathrm{~h}$.

may come from adsorbed $\mathrm{H}_{2} \mathrm{O}$ or $\mathrm{O}_{2}$ on the surface of the particles [24], and is evidently not consistent with the $\mathrm{O} 1 \mathrm{~s}$ signal of $\mathrm{ZnO}(530.5 \mathrm{eV})$ [25]. Furthermore, no particularly noticeable oxidized $\mathrm{S}$ species, such as $-\mathrm{SO}_{2}$, were detected [26]. Accordingly, the $\mathrm{ZnS}$ particle produced was a high purity compound without impurities. As shown in Fig. 4(b), a $\mathrm{ZnS}$ particle having a zinc-blende structure was observed at $1021.9 \mathrm{eV}$ and $1045.0 \mathrm{eV}$, corresponding to the binding energies of $Z n 2 p_{3 / 2}$ and $2 p_{1 / 2}$, respectively. The asymmetric $S$ $2 p$ peak in Fig. 4(c) was deconvoluted into two peaks corresponding to $\mathrm{S} 2 \mathrm{p}_{3 / 2}$ and $\mathrm{S} 2 \mathrm{p}_{1 / 2}$ and were located at 161.1 $\mathrm{eV}$ and $162.2 \mathrm{eV}$, respectively. The binding energy of 161.1 $\mathrm{eV}$ originated from $\mathrm{S}^{2-}$ in the $\mathrm{ZnS}$. The other sub-peak of approximately $162.2 \mathrm{eV}$ formed due to S-S species [26,27].

Fig. 5 is a TEM image of a $\mathrm{ZnS}$ particle synthesized through the glycothermal method at $200{ }^{\circ} \mathrm{C}$ for 1 hour. It was found that the $\mathrm{ZnS}$ nanocrystals of the primary particles aggregated with each other to form secondary particles with an average particle size of $0.4 \mu \mathrm{m}$ to $0.7 \mu \mathrm{m}$, with a nearly spherical shape. In high-resolution TEM images, the $\mathrm{ZnS}$ aggregates were found to be composed of uniform nanocrystals ranging from $4 \mathrm{~nm}$ to $5 \mathrm{~nm}$ in size. Their size was similar to the average particle size calculated using Scherrer's equation. In addition, a lattice fringe with an interplanar spacing of

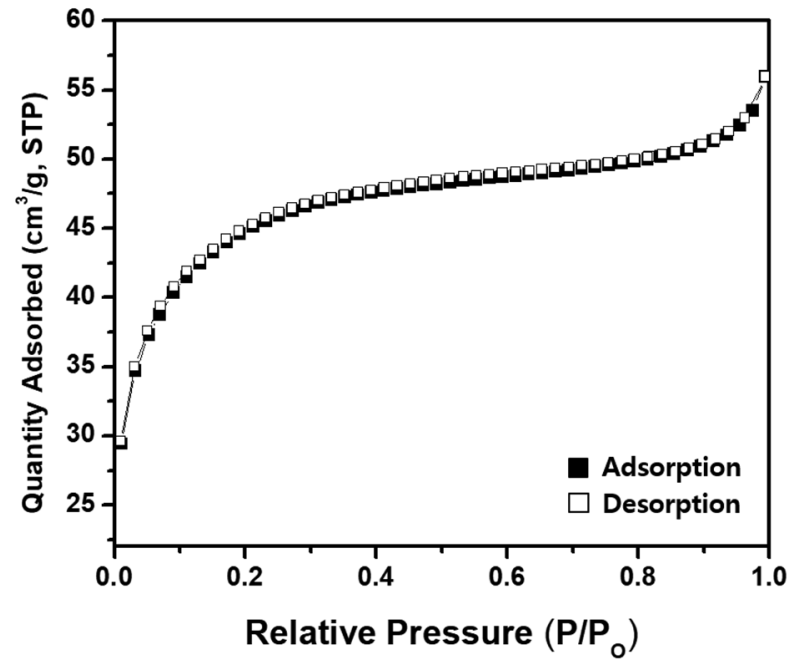

Fig. 6. Nitrogen adsorption-desorption isotherm of the selfaggregated $\mathrm{ZnS}$ particle synthesized by the glycothermal method at $200{ }^{\circ} \mathrm{C}$ for $1 \mathrm{~h}$

$0.310 \mathrm{~nm}$ was determined to be the (111) fringe of a single crystal $\mathrm{ZnS}$ nanocrystal, and it was close to the zinc-blende lattice constant of $\mathrm{ZnS}$.

Typical $\mathrm{N}_{2}$ gas adsorption-desorption isotherms for the $\mathrm{ZnS}$ particle synthesized at $200{ }^{\circ} \mathrm{C}$ for 1 hour are shown in Fig. 6 . It was found that the self-aggregated $\mathrm{ZnS}$ particle had a BET surface area of $156.1 \mathrm{~m}^{2} / \mathrm{g}$ and an average pore size and total pore volume of $3.4 \mathrm{~nm}$ and $0.087 \mathrm{~cm}^{3} / \mathrm{g}$, respectively. The 


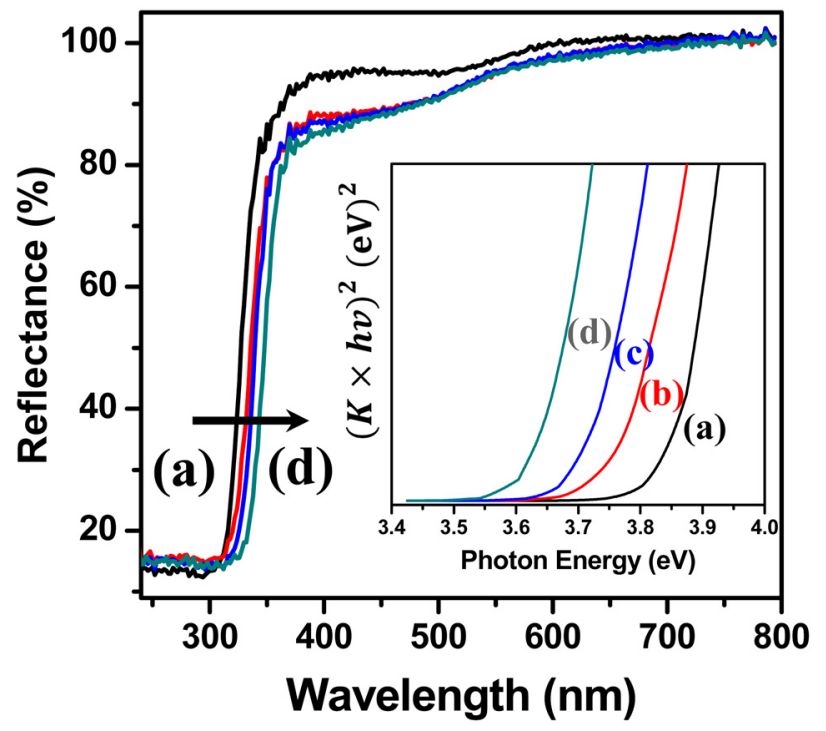

Fig. 7. UV-Vis DR spectra of the self-aggregated $\mathrm{ZnS}$ particle synthesized by the glycothermal method at (a) $125^{\circ} \mathrm{C}$, (b) $150^{\circ} \mathrm{C}$, (c) $175^{\circ} \mathrm{C}$, and (d) $200{ }^{\circ} \mathrm{C}$ for $1 \mathrm{~h}$ and a plot of $(K \times h v)^{2}$ vs. energy (hv) of the $\mathrm{ZnS}$ to determine the band gap (inset).

stated specific surface area was a high value compared to the mesoporous microsphere $\mathrm{ZnS}$ reported in the literature [26]. Although the self-assembly of $\mathrm{ZnS}$ microspheres has been reported, the macroporous $\mathrm{ZnS}$ corresponded to a type IV curve of the general IUPAC (International Union of Pure and Applied Chemistry) classification, and formed a mesopore structure between the particles on the microsphere surface. On the other hand, the adsorption-desorption isotherm obtained in Fig. 6 is a curve close to type I classification. This is considered to indicate a microporous material with a broader pore size distribution, with wide micropores and narrow mesopores [28].

Fig. 7 shows the results obtained with an ultraviolet-visible spectrophotometer and diffused reflectance spectra (DRS) of the self-aggregated $\mathrm{ZnS}$ particles synthesized by the glycothermal method at each reaction temperature. Observing the reflectance spectra of the particles produced at all reaction temperatures, it was found that strong absorption occurred in the range of about $300 \mathrm{~nm}$ to $370 \mathrm{~nm}$, which suggests that they are potentially efficient photocatalysts for UV lightdriven applications. The band gap energy was calculated using the following equation.

$$
(K \times h v)^{2}=\left(h v-\mathrm{E}_{\mathrm{g}}\right), K=\frac{(1-\mathrm{R})^{2}}{2 \mathrm{R}}
$$

where, $K$ is the Kubelka-Munk coefficient, $\mathrm{R}$ is the diffused reflectance (\%), and $h v$ is the photon energy. $K$ is obtained from $\mathrm{R}$ using the above relational expression. It is converted into $[K \cdot h v]^{2}$ vs. photon energy as shown in the inset of Fig. 7. The band gap energy of $\mathrm{ZnS}$ was calculated by the extrapolation of $[K \cdot h v]^{2}=0$. As the glycothermal reaction temperature increased, the absorption edge of $\mathrm{ZnS}$ was observed to move toward the longer wavelength, and the calculated band gap energy decreased to $3.85 \mathrm{eV}, 3.76 \mathrm{eV}, 3.70 \mathrm{eV}$, and $3.62 \mathrm{eV}$. The red-shift phenomenon of the energy band gap is reportedly due to an increase in particle size, and the internal stress in a crystal structure of small size [11,13]. It is obvious that the
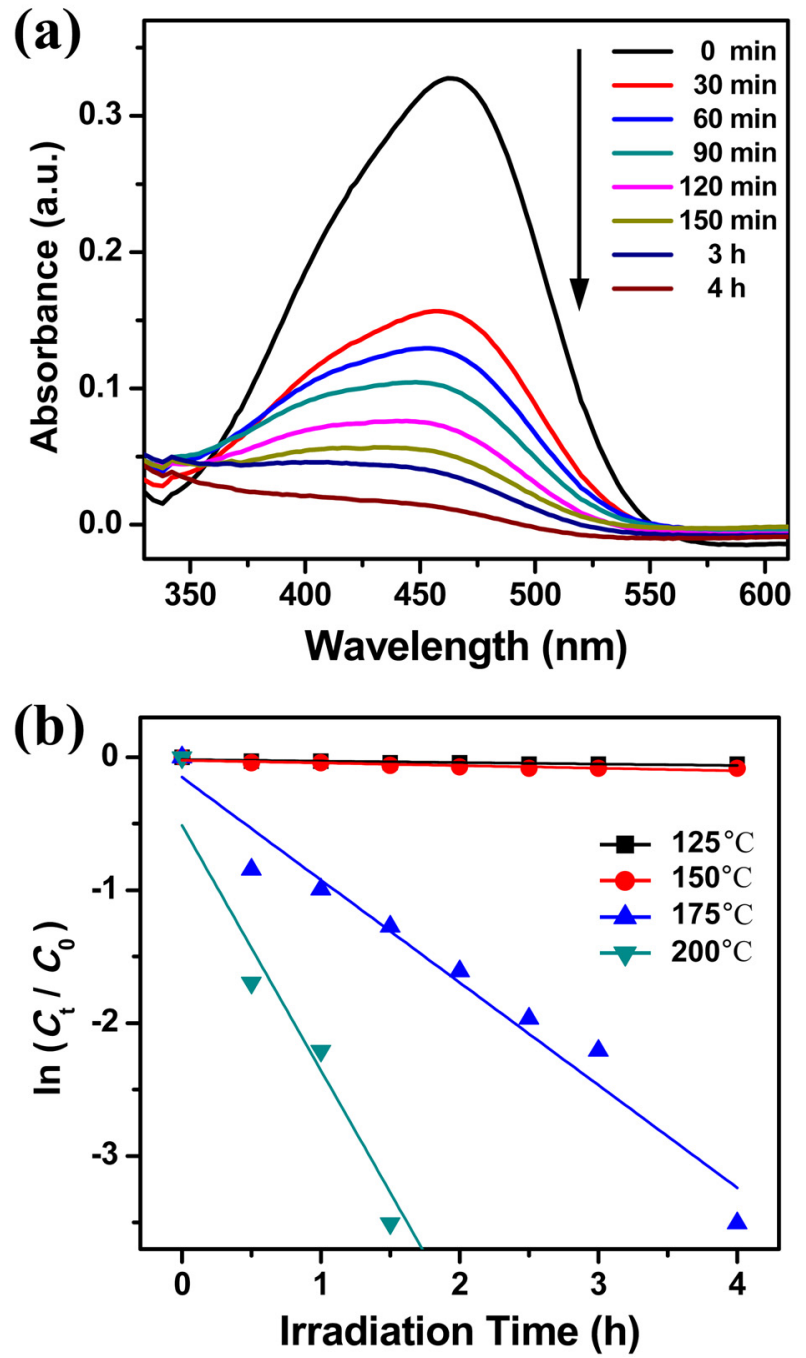

Fig. 8. (a) Absorption spectra for the decomposition of MO aqueous solutions in the presence of self-aggregated $\mathrm{ZnS}$ particles (prepared at $175{ }^{\circ} \mathrm{C}$ for $1 \mathrm{~h}$ ) measured at different UV light irradiation times; and (b) Photodecomposition rate showing MO concentration at different intervals using $\mathrm{ZnS}$ photocatalysts obtained by varying glycothermal reaction temperatures. 
bandgap variation could be attributed to changes in the size of the spherical secondary particles with the increased reaction temperature, and the internal stress in the small primary selfaggregated $\mathrm{ZnS}$ particles. In addition, it can likely be ascribed to the formation of surface defects and sulfur vacancies in the particles, as shown in the EDS results [29].

Fig. 8 shows the results of the UV spectroscopic analysis of the photocatalytic decomposition experiments using methyl orange $\left(\mathrm{MO}, \lambda_{\max }=464 \mathrm{~nm}\right.$ ), an organic dye. To evaluate the decomposition characteristics of $\mathrm{MO}$, the absorption spectral changes of the $\mathrm{ZnS}$ particle produced at $175^{\circ} \mathrm{C}$ were measured. They showed a distinct decomposition phenomenon in relation to the UV irradiation time, as shown in Fig. 8(a). As the UV irradiation time increased, the intensity of the MO absorption peak gradually decreased and about $90 \%$ of the MO was decomposed after 3 hours of irradiation. This indicates that the MO concentration decreased due to the destruction of the color development structure of the dye by the photocatalytic effect of the $\mathrm{ZnS}$. To confirm the effect on the decomposition of $\mathrm{MO}$, the change in MO photodecomposition was obtained using the following equation. UV irradiation was performed for different amounts of time, and the changes are shown in Fig. 8(b) $[11,30]$.

$$
\ln \left(\frac{C_{t}}{C_{0}}\right)=-k t
$$

where, $C_{0}$ is the initial $\mathrm{MO}$ concentration, $C_{t}$ is the $\mathrm{MO}$ concentration after UV irradiation for a certain period of time, $k$ is the reaction rate constant, and $t$ is the UV irradiation time $(\mathrm{h})$. A linear relationship plot of the pseudofirst-order reaction between $\ln \left(C_{t} / C_{0}\right)$ and $\mathrm{UV}$ irradiation time was observed for all of the self-aggregated $\mathrm{ZnS}$ particles. Their rate constants $(k)$, correlation coefficients $\left(R^{2}\right)$, and the kinetics equations can be obtained from the above equation, as shown in Table 1 .
In the $\mathrm{ZnS}$ particles produced at $175^{\circ} \mathrm{C}$ or higher, the reaction rate constant showed a steep slope, so that the dye MO rapidly decomposed within 60 minutes of irradiation, resulting in $60 \%$ of $\mathrm{ZnS}$ at $175^{\circ} \mathrm{C}$ and $90 \%$ of $\mathrm{ZnS}$ at $200{ }^{\circ} \mathrm{C}$. From Table 1, it can be concluded that the pseudo-first-order rate constant was 3 times faster when the reaction temperature was increased from $175^{\circ} \mathrm{C}$ to $200{ }^{\circ} \mathrm{C}$. In addition, the $\mathrm{ZnS}$ prepared at $200{ }^{\circ} \mathrm{C}$ showed excellent photocatalytic decomposition activities, with almost $100 \%$ decomposition in 90 minutes of irradiation. The self-aggregated $\mathrm{ZnS}$ particles prepared at $200{ }^{\circ} \mathrm{C}$ had a faster rate of reaction, corresponding to the maximum of $k$ values, indicating outstanding photocatalytic activity. However, only about $10 \%$ decomposition of MO dye molecules was achieved by the $\mathrm{ZnS}$ particle prepared at $150{ }^{\circ} \mathrm{C}$ or less, even after 4 hours of irradiation.

In $\mathrm{ZnS}$, a semiconductor compound, electron-hole pair carriers are generated by electrons excited in the conduction band and holes in the valence band due to the photoexcitation phenomenon. Super oxide anion radicals are generated by electrons photoexcited in the conduction band. The holes in the photo-induced valence band react with water and hydroxide anions to form hydroxyl radical species that are assumed to play a role in dye decomposition. The photodecomposition behavior of $\mathrm{MO}$ with the $\mathrm{ZnS}$ photocatalyst can be expressed using the following equation.

$$
\begin{aligned}
& \mathrm{ZnS}+h v \rightarrow e^{-}+h^{+} \\
& e^{-} \rightarrow \mathrm{O}_{2} \rightarrow \mathrm{O}_{2}^{\cdot-} \\
& h^{+}+\mathrm{OH}^{-} \rightarrow \mathrm{OH}^{\bullet} \\
& \mathrm{O}_{2}^{\cdot-}+\mathrm{H}^{+} \rightarrow \mathrm{HO}_{2}^{\cdot} / \mathrm{OH} \\
& \mathrm{H}_{2} \mathrm{O} / \mathrm{OH}^{-}+h^{+} \rightarrow \mathrm{OH}^{\bullet} \\
& \mathrm{MO}^{\bullet}+\mathrm{OH}^{\bullet} \rightarrow \text { Decomposition products }\left(\mathrm{CO}_{2}, \mathrm{H}_{2} \mathrm{O}\right)
\end{aligned}
$$

Recent studies have reported that the efficiency of photodecomposition can be improved by controlling the particle size, specific surface area, and band gap of the

Table 1. Parameters and linear kinetic equations of MO photocatalytic reactions of the samples prepared at different glycothermal reaction temperatures.

\begin{tabular}{cccc}
\hline Photocatalyst & $k\left(\mathrm{~h}^{-1}\right)$ & First-order kinetic equation & $R^{2}$ \\
\hline $125^{\circ} \mathrm{C}$ & 0.0111 & $\ln \left(C_{t} / C_{0}\right)=-0.0111 t-0.0169$ & 0.7343 \\
$150^{\circ} \mathrm{C}$ & 0.0198 & $\ln \left(C_{t} / C_{0}\right)=-0.0198 t-0.0225$ & 0.7956 \\
$175^{\circ} \mathrm{C}$ & 0.7725 & $\ln \left(C_{t} / C_{0}\right)=-0.7725 t-0.1500$ & 0.9634 \\
$200^{\circ} \mathrm{C}$ & 2.2062 & $\ln \left(C_{t} / C_{0}\right)=-2.2062 t-0.1979$ & 0.9630
\end{tabular}


photocatalyst materials [26,30-32]. In this study, although the size of the secondary particles of the produced $\mathrm{ZnS}$ particle increased when the glycothermal reaction temperature increased, excellent photocatalytic activities were obtained because of its crystallization, and also because the particle is made of self-aggregated and uniform small primary nanocrystals. This leads to a large reaction-specific surface area. In addition, when photo-excited by a UV light source of $365 \mathrm{~nm}$, the $\mathrm{ZnS}$ particles produced at $150^{\circ} \mathrm{C}$ or less had a wider band gap. Therefore, sufficient photo-excitation did not occur. However, the $\mathrm{ZnS}$ particles produced at $175^{\circ} \mathrm{C}$ or higher showed an improved photodecomposition efficiency by generating electron-hole pair carriers with sufficient photoexcitation in a narrow band gap.

\section{Conclusions}

In this study, self-aggregated $\mathrm{ZnS}$ crystalline particles were successfully produced at various reaction temperatures using the glycothermal method, a simple and environmentally friendly particle manufacturing method. The physical properties of the particles produced and the photodecomposition characteristics of the photocatalytic material were investigated using methyl orange (MO) dye. The $\mathrm{ZnS}$ particle crystallized at a relatively low reaction temperature of $125^{\circ} \mathrm{C}$ was found to have a zinc-blende crystal structure. The $\mathrm{ZnS}$ particle sizes could be controlled by the glycothermal reaction temperature. An agglomerated secondary particle with a size of about $0.5 \mu \mathrm{m}$ to $0.7 \mu \mathrm{m}$ and a spherical shape were formed from uniform primary nanocrystals of about $4 \mathrm{~nm}$ as the reaction temperature increased. The self-aggregated $\mathrm{ZnS}$ particles were produced by the glycothermal method at $200{ }^{\circ} \mathrm{C}$ for 1 hour without using any additives such as surfactants or capping agent. The result was a high purity $\mathrm{ZnS}$ compound without impurities, with a theoretically stoichiometric ratio. The photodecomposition properties of the self-aggregated $\mathrm{ZnS}$ particle were measured with $\mathrm{MO}$, and it was found that as the irradiation time under a UV light source $(365 \mathrm{~nm})$ increased, the MO concentration decreased as the MO was decomposed. The rate of photodecomposition was high for the self-aggregated $\mathrm{ZnS}$ particles produced at $175^{\circ} \mathrm{C}$ or higher. In particular, the self-aggregated $\mathrm{ZnS}$ particle produced at $200{ }^{\circ} \mathrm{C}$ had a large specific surface area and a narrow energy band gap of about $3.62 \mathrm{eV}$ in a UV light source, so that the electron-hole pair carriers generated by photoexcitation improved the photodecomposition efficiency of the organic dye. For each different glycothermal reaction temperature, a self-aggregated $\mathrm{ZnS}$ particle with excellent crystallization was obtained, and it was found that it significantly affected the photocatalytic decomposition performance.

\section{Acknowledgment}

This work was supported by the PaiChai University research grant in 2020 (No. 2020A0128).

\section{REFERENCES}

1. X. Fang, T. Zhai, U. K. Gautam, L. Li, L. Wu, Y. Bando, and D. Golberg, Prog. Mater. Sci. 56, 175 (2011).

2. G. J. Lee and J. J. Wu, Powder Technology 318, 8 (2017).

3. D. Y. Lee, H. M. Kang, J. M. Yoon, and J. G. Lee, Korean J. Mater. Res. 26, 100 (2016).

4. M. Dür, S. Goodnick, S. S. Pennathur, J. F. Wager, M. Reigrotzki, and R. Redmer, J. Appl. Phys. 83, 3176 (1998).

5. H. Katayama, S. Oda, and H. Kukimoto, Appl. Phys. Lett. 27, 697 (1975).

6. N. Üzar, Sensor Lett. 83, 808 (2016).

7. S. Ummartyotin and Y. Infahsaeng, Renewable and Sustainable Energy Reviews 55, 17 (2016).

8. S. K. Mishra, D. Kumar, A. M. Biradar, and Rajesh, Bioelectrochemistry 88, 118 (2012).

9. Y. Kim, S. J. Kim, S. P. Cho, B. H. Hong, and D. J. Jang, Sci. Rep. 5, 12345 (2015).

10. S. Kahng and J. H. Kim, Korean J. Met. Mater. 58, 907 (2020).

11. Z. Yea, L. Kong, F. Chen, Z. Chen, Y. Lin, and C. Liu, Optik 164, 345 (2018).

12. J. S. Hu, L. L. Ren, Y. G. Guo, H. P. Liang, A. M. Cao, L. J. Wan, and C. L. Bai, Angew. Chem. Int. Ed Engl. 44, 1269 (2005).

13. M. M. H. Farooqi and R. K. Srivastava, Mater. Sci. Semicond. Process 20, 61 (2014).

14. K. Hedayati, A. Zendehnam, and F. Hassanpour, J. Nanostruct. 6, 207 (2016).

15. H. Wu, Q. Wang, Y. Yao, C. Qian, X. Zhang, and X. Wei, J. Phys. Chem. C 112, 16779 (2008). 
16. J. Li, Q. Zhang, L. An, L. Qin, and J. Liu, J. Solid State Chem. 181, 3116 (2008).

17. F. Dong, Y. Guo, J. Zhang, Y. Li, L. Yang, Q. Fang, H. Fang, and K. Jiang, Mater. Lett. 97, 59 (2013).

18. J. Y Park, D. Y. Choi, K. J. Hwang, S. J. Park, S. D. Yoon, Y. H. Yun, X. G. Zhao, H. B. Gu, and I. W Lee, J. Nanosci. Nanothechnol. 15, 5224 (2015).

19. H.-S. Kil, Y.-J. Jung, J.-I. Moon, J.-H. Song, D.-Y. Lim, and S.-B. Cho, J. Nanosci. Nanotechnol. 15, 6193 (2015).

20. J.-H. Ryu, K. Phimmavong, D.-Y. Lim, S.-B. Cho, and J.-H. Song, Ceram. Int. 42, 17565 (2016).

21. B.D. Cullity and S.R. Stock, Elements of X-Ray Diffraction, 3rd ed. p.167-171, Prentice-Hall Inc., Upper Saddle River, New Jersey, USA (2001).

22. B Y. Zhao, Y. Zhang, H. Zhu, G. C. Hadjipanayis, and J. Q. Xiao, J. Am. Chem. Soc. 126, 6874 (2004).

23. Y. Liu, J.C. Hu, C. Ngo, S. Prikhodko, S. Kodambaka, J. Li, and R. Richards, Appl. Catal. B: Environ. 106, 212 (2011).

24. J. Yu, J. Zhang and S. W. Liu, J. Phys. Chem. C 114, 13642
(2010).

25. G. Deroubaix and P. Marcus, Surf. Interface Anal. 18, 39 (1992).

26. M. Muruganandhama, R. Amutha, E. Repo, M. Sillanpää, Y. Kusumoto, Md. Abdulla-Al-Mamun, J. Photochem. Photobiol. A: Chem. 216, 133 (2010).

27. S. Ham, Y. Kim, M. J. Park, B. H. Hong, and D. J. Jang, RSC Adv. 6, 24115 (2016).

28. M. Thommes, K. Kaneko, A. V. Neimark, J. P. Olivier, F. Rodriguez-Reinoso, J. Rouquerol, and K.S.W. Sing, Pure Appl. Chem. 87, 1051 (2015).

29. Y. Liu, J.C. Hu, T. Zhou, R. Che, and J. Li, J. Mater. Chem. 21, 16621 (2011).

30. W. Yang, X. Liu, D. Li, L. Fan, and Y. Li, Phys. Chem. Chem. Phys. 17, 14532 (2015).

31. W.L. Cen, T. Xiong, C.Y. Tang, S.D. Yuan, and F. Dong, Ind. Eng. Chem. Res. 53, 15002 (2014).

32. L. Yin, D. Zhang, D. Wang, X. Kong, J. Huang, F. Wang, and Y. Wu, Mater. Sci. Eng. B 208, 15 (2016). 